This is the author's final, peer-reviewed manuscript as accepted for publication. The publisher-formatted version may be available through the publisher's web site or your institution's library.

\title{
Laboratory evaluation of attract-and-kill formulations against the Indianmeal moth, Plodia interpunctella (Hübner) (Lepidoptera: Pyralidae)
}

Manuel Campos and Thomas W. Phillips

\section{How to cite this manuscript}

If you make reference to this version of the manuscript, use the following information:

Campos, M., \& Phillips, T. W. (2013). Laboratory evaluation of attract-and-kill formulations against the Indianmeal moth, Plodia interpunctella (Hübner) (Lepidoptera: Pyralidae). Retrieved from http://krex.ksu.edu

\section{Published Version Information}

Citation: Campos, M., \& Phillips, T. W. (2013). Laboratory evaluation of attract-and-kill formulations against the Indianmeal moth, Plodia interpunctella (Hübner) (Lepidoptera: Pyralidae). Journal of Stored Products Research, 52, 12-20.

Copyright: (c) 2012 Elsevier Ltd.

Digital Object Identifier (DOI): doi:10.1016/j.jspr.2012.09.005

Publisher's Link:

http://www.sciencedirect.com/science/article/pii/S0022474X1200077X

This item was retrieved from the K-State Research Exchange (K-REx), the institutional repository of Kansas State University. K-REx is available at http://krex.ksu.edu 
1 Journal of Stored Products Research

2

3

4 LABORATORY EVALUATION OF ATTRACT-AND-KILL

5 FORMULATIONS AGAINST THE INDIANMEAL MOTH,

$6 \quad$ Plodia interpunctella (Hübner) (Lepidoptera: Pyralidae)

9 Manuel Campos ${ }^{1}$ and Thomas W. Phillips ${ }^{2}$

10 Department of Entomology and Plant Pathology

11127 Noble Research Center

12 Oklahoma State University

13 Stillwater, OK 74078 USA

14

15

16

17

$18{ }^{1}$ Current address: C\&M Pest Control and Consultants, Dallas, TX USA

$19{ }^{2}$ Author for correspondence at current address: Department of Entomology, 123 Waters Hall,

20 Kansas State University, Manhattan, KS 66506 USA

21

22

23

24 


\section{Abstract}

26 Pheromone-based population suppression methods for stored-product insects can reduce or

27 eliminate application of chemical insecticides near finished food products. The responses of

28 adult male Indianmeal moth males (IMM), Plodia interpunctella (Hübner), to the attract-and-kill

29 formulations of a gel, a flat wax panel, and a plastic cylinder device, mixed or sprayed with the

30 pyrethroid insecticides permethrin, cyfluthrin, or organically compliant natural pyrethrin,

31 combined with the synthetic female sex pheromone (Z,E) -9,12 tetradecadienyl acetate, were

32 evaluated in a laboratory wind tunnel. The wax panel and cylinder, which utilized controlled-

33 release pheromone lures, were more attractive to IMM males over the course of an eight-week

34 aging period than was the gel, which had the pheromone incorporated into the gel matrix. The

35 contact time for responding males was longer on the wax panel and plastic cylinder than on the

36 gel formulation. The percentage of mortality of males was higher with wax panels formulated

37 with cyfluthrin at $6.0 \% \mathrm{AI}$, permethrin at $6.0 \% \mathrm{AI}$ and the cylinder formulated with cyfluthrin at

$382.0 \%$ AI, compared to the gel over the eight-week study. These same formulations had the

39 greatest impact on egg-laying by females paired with treated males and on the percent of eggs

40 that hatched. Of all the attract-and-kill formulations tested, the most promising for field

41 applications to suppress IMM pest populations was the wax panel containing $6.0 \%$ AI of either

42 cyfluthrin or permethrin.

43 Key words: Wind tunnel, attracticide, pheromone, stored-products, residual insecticides 


\section{Introduction}

46 Semiochemically-based pest management techniques such as mating disruption, mass

47 trapping and attract-and-kill have been developed as alternatives to traditional insecticides

48 applications to control important pest Lepidoptera. Many of these techniques use synthetic sex

49 pheromones to attract males in close contact with killing agent (attract-and-kill), but not

50 necessary in close contact with the pheromone source (mass-trapping, El-Sayed et al., 2006), or

51 otherwise interrupt male mating behavior so that females go unmated and the population

52 declines. However, the most common use of synthetic pheromones for stored product moths is

53 for monitoring populations, and this has become part of the integrated pest management

54 programs for these pests (Burkholder \& Ma, 1985; Vick et al., 1981; 1986; Arthur et al., 1991;

55 Phillips et al., 2000, Phillips and Throne, 2010). The predominate female pheromone of Plodia

56 interpunctella (Hubner) (Lepidoptera: Pyralidae) is (Z,E) $-9,12$ tetradecadienyl acetate, is

57 commonly referred to as ZETA (Brady et al., 1971; Kuwahara et al., 1971; Kuwahara \& Casida,

58 1973; Sower et al., 1974; Soderstrom et al., 1980; Teal et al., 1995; Zhu et al., 1999).

59 The attract-and-kill, or "attracticide", method of pest control incorporates an attractant of a

60 target insect species with an insecticide in order to kill large numbers of responding insects and

61 ultimately reduce a pest population (Lanier, 1990). The LastCall® gel (IPM Tech, Inc.,

62 Portland, OR), which is a combination of a synthetic sex pheromone with the synthetic

63 pyrethroid permethrin in a gel matrix, was formulated to control Oriental fruit moth, Grapholita

64 molesta (Evenden \& McLaughlin, 2004, 2005; Evenden et al., 2005), Codling moth, Cydia

65 pomonella (L.) (Krupke et al., 2002; Evenden \& McLaughlin, 2005), and it showed promise for

66 the Indianmeal moth, Plodia interpunctella (Nansen \& Phillips, 2004). 
The Indianmeal moth, Plodia interpunctella (Hübner), is one of the most serious stored-

68 product insect pests of value-added food products worldwide, and there is substantial interest in

69 developing safe and effective alternatives to traditional residual and fumigant chemical control of

70 this pest (Arthur \& Phillips, 2003; Phillips, 2006). Efficacy of the attract-and-kill method, in

71 which reproduction is impacted after large numbers of males are killed following contact with

72 point-sources that have pheromone combined with an effective contact insecticide, was

73 demonstrated for P. interpunctella by Nansen \& Phillips (2004). However, that study examined

74 only one attract-and-kill gel-based formulation, and it did not assess the activity of the tested gel

75 formulation over time. A study with aged gel formulations would have helped predict the time

76 period over which it would remain active in practical pest control applications.

77 The broad objective of our work has been to develop an effective attract-and-kill technology

78 for $P$. interpunctella. We initially evaluated a variety of contact insecticides against male $P$.

79 interpunctella for residual activity, and determined that natural pyrethrum and synthetic

80 pyrethroids had very good activity in simple surface-contact bioassays (Campos and Phillips

81 2010). In the current study described below we evaluated the efficacy of three types of attract-

82 and-kill devices, each with previously determined active insecticide formulations, in a wind

83 tunnel activity against $P$. interpunctella males. The efficacy of these attract-and-kill

84 formulations was based on male contact with a treated substrate following upwind flight to a

85 pheromone lure, male mortality, and reproductive fitness of surviving males when paired with

86 females. We evaluated the residual activity of these attract-and-kill formulations at five different

87 times over a period of eight weeks. 
$90 \quad$ 2.1. Insects.

$91 \quad$ P. interpunctella male and female adults from the laboratory culture at Oklahoma State

92 University were reared on a diet containing corn meal, chick starter, egg crumbles and glycerol

$93(4: 2: 2: 1)$ in 425-ml glass jars (Alltrista, Muncie, IN) placed in a growth chamber at $28{ }^{\circ} \mathrm{C}, 60-70$

$94 \%$ r.h., and L16:D8 photoperiod. Corrugated cardboard rolls $(1 \times 5 \mathrm{~cm})$ were placed into the

95 culture jars for the last-stage wandering larvae to crawl into and pupate. The pupae were

96 removed from the cardboard rolls, separated by sex and placed individually into 1.0-dram vials

97 with ventilated plastic caps (Fisher Scientific, Pittsburg, PA, USA) and returned to the growth

98 chamber until they emerged as adults. For these experiments, 1-2- day-old virgin adults were

99 used and each adult was used only once.

100

$101 \quad$ 2.2. Wind tunnel

102 The wind tunnel used consisted of a wood frame $(\mathrm{W}=91 \mathrm{~cm}, \mathrm{H}=91 \mathrm{~cm}, \mathrm{~L}=182 \mathrm{~cm})$ with

103 side walls and roof made of rigid Plexiglass ${ }^{\circledR}$. The floor of the tunnel was an aluminum sheet

104 and the two ends of the tunnel were covered by conventional window fly screening to prevent

105 escape of moths. The down-wind end of the tunnel had a plenum that reduced the $91-\times 91-\mathrm{cm}$

106 square-opening to a circular-opening (38-cm i.d.) with an exhaust fan driven by an electric motor

107 equipped with a rheostat to adjust exhaust wind speed. Air was exhausted from the tunnel via a

108 pipe (38-cm i.d.) directly out of the room and to the exterior of the building so that contaminated

109 air could not re-enter the tunnel. Room air was drawn into the tunnel at the upwind end by the

110 suction of the exhaust fan and passed through an activated charcoal-impregnated filter to provide

111 relatively clean air to the tunnel for flight assays. Wind speed in the tunnel was measured with 
112 smoke tests using titanium tetrachloride (J.T.Baker, Phillipsburg, NJ, USA) and was set at $60 \mathrm{~cm}$

113 per second for all tests, which was observed to give relatively even laminar flow through the

114 central core of the tunnel from upwind to downwind end.

115 Insects and test materials were prepared in a separate room, and only brought into the wind

116 tunnel room when a specific test was to be conducted to minimize contamination of room air

117 between assays. Controlled conditions maintained in the wind tunnel room were $26-28{ }^{\circ} \mathrm{C}, 50$ -

$11860 \%$ r.h., and lights provided by four fluorescent tubes, $60 \mathrm{~W}$ each, suspended over the tunnel

119 roof.

120

121 2.3. Formulations tested and experimental procedures

122 Three sets of experiments, each one with a different type of attract-and-kill formulation, were 123 conducted. The first tested was LastCall ${ }^{\circledR}$ gel (IPM Tech, Inc., Portland, OR, USA) with the

124 following formulations that each contained the synthetic female pheromone $Z, E-9,12-$

125 tetradecadienyl acetate at $0.16 \%$ by weight; permethrin $6.0 \%$ active ingredient (AI), pyrethrin

$126 \quad 6.0 \% \mathrm{AI}$, and gel with no insecticide but with the synthetic female pheromone only as an

127 attractant to serve as a non-insecticide "blank" control. These formulations were tested as

128 droplet sizes of 50 - or 100-mg applied to the surface of a glass microscope slide $(7.6 \times 2.5 \mathrm{~cm}$,

129 Sargent-Welch, USA) and held in place at the upwind end of the tunnel with a small binder clip

130 (ACCO, USA) suspended from a laboratory stand.

131 The second attract-and-kill formulation was a wax panel $(20 \times 13 \mathrm{~cm}$; Suterra, Bend, OR,

132 USA) that contained the AI cyfluthrin at $0.01,0.1,1.0$ and $6.0 \%$, or permethrin at $6.0 \%$ AI and

133 deployed with a controlled release pheromone lure containing the synthetic female pheromone

134 (Biolure ${ }^{\circledR}$ by Suterra, Bend, OR, USA) placed in the center of the wax panel; and a control wax 
135 panel, with no insecticide, deployed with the pheromone lure "blank". The material structure of

136 the wax panel was a paper fiberboard panel that was coated with a mixture of paraffin and oil

137 that contained the insecticide. The Biolure ${ }^{\circledR}$ pheromone release device was a sealed, thin foil

138 pouch for which the bottom and most of the top surface were impermeable film that contained a

139 reservoir of liquid pheromone, and the pheromone was evaporated through a semi-permeable

140 membrane that controlled the release rate by its size and structure.

141 Finally, the third device was a plastic mesh cylinder $(7 \mathrm{~mm}$ mesh; 35 -cm height $\times 10$-cm i.d.;

142 Uniek Co., USA). Insecticides were sprayed onto the cylinders until run-off with an artist's air

143 brush (Paasche, USA), and were either permethrin (FMC Co., Philadelphia, PA, USA),

144 cyfluthrin (Bayer, Kansas City, MO, USA) or organically-compliant pyrethrin without the

145 synergist PBO (Pyperonyl Butoxide; McLaughlin Gormley King Co., Minneapolis, MN, USA),

146 each at $2.0 \% \mathrm{AI}$ in the final mix and deployed with a Suterra Biolure ${ }^{\circledR}$ in the middle of the

147 cylinder. A cylinder without insecticide, but with a pheromone lure was used as a control

148 "blank". Attract-and-kill devices were suspended on a laboratory stand at the mid-point of the 149 upwind end of the wind tunnel.

150 Two-day old virgin adult male $P$. interpunctella were released from a cage held on a

151 laboratory stand at the middle of the downwind end of the tunnel. Five adult males were

152 released inidividually in the wind tunnel and bioassayed against each replicate of each device

153 type. Each male moth was given a maximum of $5 \mathrm{~min}$ to take flight and respond upwind to the

154 device and contact it. Moths that did not touch the device in 5 min were considered as "no

155 response" and scored 0 for analysis of the males that landed on the device only; those males that 156 contacted the device were scored as responders. 
The percentage of moths in a test group contacting each device, and time each male was in

158 contact with a device, were recorded. Once a male finished contact and flew away from the

159 device it was captured and placed into a 425-ml glass jar with a virgin female moth and $15 \mathrm{~g}$ of

160 cracked wheat kernels as a substrate for egg laying. Every male-female pair was kept for $24 \mathrm{~h}$ in

161 a growth chamber at $28^{\circ} \mathrm{C}, 60-70 \%$ r.h., and L16:D8 photoperiod.

162 Male mortality was recorded after $24 \mathrm{~h}$. Eggs laid in the wheat were carefully separated from

163 the wheat using a U.S. no. 14 sieve (Seedburo Equipment Company, USA), counted and placed

164 on double-sided tape on a 9-cm-diameter black filter paper (Ahlstrom, Mt Holly Springs, PA,

165 USA) in a 9-cm-diameter Plastic Petri dishes (Fisher Scientific, Canada). The eggs were placed

166 into a growth chamber at $28^{\circ} \mathrm{C}, 60-70 \%$ r.h., and L16:D8 photoperiod for 5 days, after which

167 the the number hatched eggs was recorded.

\section{2.4. Statistical Analysis}

170 Data for each of the three attract-and-kill formulations were analyzed as three separate 171 experiments within a time period, and comparisons were made for each specific formulation 172 (e.g., applied insecticide concentration of a particular device type) across time periods. Each 173 device formulation type was treated with different concentrations of insecticides and four 174 replicates of each device type-insecticide concentration were established. A total of 20 males 175 were tested within four blocks of each device type. Each adult male in a group of five was 176 released individually and used only once.

177 The attract-and-kill formulations were tested in the wind tunnel at $0,4,6$, and 8 weeks after 178 being established, and they were held and aged in a room separate from the wind tunnel between 
179 testing times. The experimental design used for each attract-and-kill formulation was a

180 randomized complete block design with four replicates. Each replicate was treated as a block.

181 The observations assessed were the percentage of released males that landed on and made

182 contact with the device, the time in seconds each adult male was in contact with a given device

183 (contact time), the percentage of male mortality of those that made contact, the number of eggs

184 laid per female, and the percentage of these eggs that hatched per female. Proportions

185 (percentages) were transformed by the arcsine-square root function prior to analysis. Data were

186 analyzed with the procedure PROC MIXED in SAS/STAT 9 for Windows (SAS Institute, 2005),

187 and the repeated measures option assuming an autoregressive covariance structure was used.

188 Every attract-and-kill device type was analyzed separately. Every treatment was compared

189 across the test period times $(0,2,4,6$, or 8 weeks $)$ and treatment differences were compared

190 within each time period. Treatments compared across and within each time period were

191 analyzed with pair wise t-tests and comparisons were protected by examining the SLICE

192 OPTION within the Least Square Means statement at $\alpha=0.05$ level.

193 


\section{3. Results}

\subsection{Device contact}

197 Fig. 1 shows the mean percentage of $P$. interpunctella adult males that contacted the attract-

198 and-kill devices within five minutes in the wind tunnel. Statistical analyses of the LastCall@ gel

199 formulations (Fig. 1a) across the entire eight-week experiment did not show significant

200 differences for contact behavior among the two insecticide active ingredients and blank gels $\left(\mathrm{F}_{2}\right.$,

$201567=1.82 ; \mathrm{P}=0.1633$ ), or the amount tested, $50 \mathrm{mg}$ or $100 \mathrm{mg}$ each, for Permethrin and

202 Pyrethrin in the gels $\left(\mathrm{F}_{1,567}=0.04 ; \mathrm{P}=0.8492\right)$. Also, significant differences were not found on

203 the interactions of insecticide treatment and weeks $\left(\mathrm{F}_{8,567}=1.69 ; \mathrm{P}=0.0970\right)$, interactions of

204 amounts of the two insecticide gels and weeks $\left(\mathrm{F}_{4,567}=0.58 ; \mathrm{P}=0.6781\right)$, and interactions

205 among insecticide active ingredient, amount of the gel used and weeks of aging of the gel

206 formulations $\left(\mathrm{F}_{8,567}=1.24 ; \mathrm{P}=0.2750\right)$. However, there was a significant interaction effect of

207 active ingredient tested and the two amounts of gel for each $\mathrm{AI}\left(\mathrm{F}_{2,567}=4.73 ; \mathrm{P}=0.0092\right)$.

208 Landing and contact responses of moths varied significantly in some cases when compared

209 across gel types within a given bioassay week, and also across weeks within a particular gel type.

210 At week 0 , the highest percentage of landing by male moths was 55\% for the Blank $100 \mathrm{mg}$ and

211 Permethrin $50 \mathrm{mg}$, and the lowest was on Permethrin $100 \mathrm{mg}$ at 20\%. At week 2, 4, and 6, there

212 was no significant difference in percent contact among treatments. By week 8 responses to the

213 gels were very low, but with some difference among treatments (Fig. 1a). When comparing

214 across bioassay times the maximum landing by males on the gel formulations was observed at

215 week 2, when responses ranged from 70 to $85 \%$. 
Analysis of the percentage of males landing on the wax panel devices (Fig. 1b) showed no

217 statistical difference among treatments for the whole experiment $\left(\mathrm{F}_{5,567}=1.01 ; \mathrm{P}=0.4117\right)$, nor

218 for treatments within weeks $\left(\mathrm{F}_{20,567}=1.30 ; \mathrm{P}=0.1733\right)$. The comparison of the moths that

219 contacted the panels across the eight-week period shows that at week 0 , less than $25 \%$ of moths

220 landed on the device. This response increased to 90 to $100 \%$ from week 2 to the end of the

221 experiment. At week 0, the formulations Blank and Cyfluthrin at 0.01 and $0.1 \%$ elicited $25 \%$ or

222 less of landing, which were statistically different from the Cyfluthrin 1.0 and 6.0\%, and

223 Permethrin 6.0\%, at 5\% landing for each (Fig. 1b). However, Cyfluthrin $0.1 \%$ was statistically

224 similar to Cyfluthrin 1.0\%. At week 2, all treatments elicited 90 to $100 \%$ landing by males and it

225 was similar up to the end of the experiment at week 8.

226 The percentage of moths landing on the plastic cylinder (Fig. 1c) was observed to be

227 significantly different among treatments overall $\left(\mathrm{F}_{3,377}=3.74 ; \mathrm{P}=0.0113\right)$ and treatments within

228 weeks $\left(\mathrm{F}_{12,377}=2.18 ; \mathrm{P}=0.0121\right)$. At week 0, Blank and Cyfluthrin $2.0 \%$ showed attractiveness

229 of 50 and $60 \%$ respectively, significantly greater than the other treatments. At week 2 ,

230 Cyfluthrin and Pyrethrin 2.0\% elicited 85 and 80\% landing, respectively, and were statistically

231 similar. Pyrethrin 2.0\% did not differ from Blank (65\% landing). However, these treatments

232 differed from Permethrin 2.0\%, which showed the lowest landing rate of $45 \%$ in week 2 . From

233 week 4 to the end of the experiment at week 8 , all treatments elicited $100 \%$ landing by tested

234 males onto the plastic cylinder devices. These plastic cylinder devices used the same

235 commercial pheromone lures as the wax panel formulations, and similar patterns of response

236 were observed during other weeks for the two devices. At week 0, there was low response and

237 from week 4 to the end of the experiment there was 100\% landing of all 20 males (5 males in

238 four replicates) for all wax panel and cylinder devices. 
240 The contact time, which was the time in seconds that adult males were in contact with

241 devices tested, is shown in Fig. 2. The gel-like formulations (Fig. 2a) all had relatively short

242 contact times and did not show significant differences among amounts of gel (i.e., $50 \mathrm{mg}$ vs. 100

$\left.243 \mathrm{mg} ; \mathrm{F}_{1,570}=0.19 ; \mathrm{P}=0.6594\right)$, in the interaction of gel amount and week of the bioassay $\left(\mathrm{F}_{4,570}\right.$

$244=0.96 ; \mathrm{P}=0.4300)$, or in the interaction among treatment $\mathrm{AI}$, amount of gel and week $\left(\mathrm{F}_{8,570}=\right.$

245 1.66; $\mathrm{P}=0.1059)$ for the whole experiment. The AI treatments were significantly different $\left(\mathrm{F}_{2}\right.$,

$246570=3.69 ; \mathrm{P}=0.0255)$, AI treatments within weeks among gel types $\left(\mathrm{F}_{8,570}=2.20 ; \mathrm{P}=0.0259\right)$

247 and amount of gel within weeks $\left(\mathrm{F}_{2,570}=5.67 ; \mathrm{P}=0.0036\right)$ for moth contact time over the whole 248 experiment.

249 All gel treatments, when analyzed across the eight-week period, showed the highest contact 250 time at week 2 , and they were significantly different from the rest of the weeks. At week 0 the 251 Blank (100 mg) and Permethrin (50 mg) gel formulations were statistically similar and showed 252 the highest contact time ( 0.8 and 0.75 seconds, respectively), but they differed statistically from 253 Pyrethrin $50 \mathrm{mg}$ and Permethrin $100 \mathrm{mg}$, which had the lowest contact times. All these 254 treatments were statistically similar to the rest of the treatments. At week 2 Permethrin $50 \mathrm{mg}$ 255 showed the longest contact time, with a mean of 1.5 seconds, and it was significantly different 256 from the formulations with Pyrethrin 50 and $100 \mathrm{mg}$. At week 4, all treatments were statistically 257 similar, and at weeks 6 and 8 the contact times were very brief and differences were slight 258 among gel types, though statistically significant.

259 Analysis of male contact time on the wax panel formulations (Fig. 2b) revealed that there 260 were significant differences among AI treatments overall $\left(\mathrm{F}_{5,570}=2.23=; \mathrm{P}=0.0498\right)$ and among 261 treatments within weeks $\left(\mathrm{F}_{20,570}=3.44 ; \mathrm{P}<0.0001\right)$. At week 0 , when pheromone lures were 
262 fresh from their storage packages and residual insecticides were recently applied, all wax panel

263 treatments had very short contact times when compared to the rest of the weeks, which were

264 statistically similar to each other. At week 2, the panels with Cyfluthrin at 6\% had the longest

265 mean contact time of 13.8 seconds, while Permethrin at $6.0 \%$ had the shortest time of 7.1

266 seconds. Conversely, at week 4 Permethrin at $6.0 \%$ had the longest contact time at 12.4 seconds,

267 while Cyfluthrin at $0.01 \%$ had the lowest contact time at 5.6 seconds. At week 6, Cyfluthrin

$2680.01 \%$, Cyfluthrin $0.1 \%$ and Permethrin $6.0 \%$ did not differ statistically, but they were

269 significantly different from Cyfluthrin $1.0 \%$ and $6.0 \%$. Cyfluthrin $6.0 \%$ and Permethrin $6.0 \%$ did

270 not differ statistically from the rest of the treatments at week 6. Contact times on wax panels at

271 week 8 were statistically similar to those observed at week 6.

272 Analysis of contact times for the plastic cylindrical (Fig. 2c) device formulations showed a

273 significant difference among AI treatments overall $\left(\mathrm{F}_{3,380}=8.58 ; \mathrm{P}<0.0001\right)$ and AI treatments

274 within weeks $\left(\mathrm{F}_{12,380}=1.82 ; \mathrm{P}=0.0436\right)$. As with wax panels, contact times on plastic cylinders

275 were short at time 0 and then were longer in most cases from bioassay time 2 weeks through 8

276 weeks, with the longest mean contact time observed for males on cylinders with Cyflthrin at

$277 \quad 2.0 \% \mathrm{AI}$.

278 3.3. Male mortality after contact

279 Fig. 4 shows the percentage mortality of adult male P. interpunctella 24-h after contacting

280 the attract-and-kill devices. For the gel formulations (Fig. 3a) there were no significant

281 difference among amounts of gel $\left(\mathrm{F}_{1,567}=0.60 ; \mathrm{P}=0.4380\right)$, interaction of gel amounts within

282 week $\left(\mathrm{F}_{4,567}=0.14 ; \mathrm{P}=0.9664\right)$, interaction of $\mathrm{AI}$ treatment by gel amount $\left(\mathrm{F}_{2,567}=1.96 ; \mathrm{P}=\right.$

283 0.1422), or AI treatment by gel amount by week $\left(\mathrm{F}_{8,567}=1.62 ; \mathrm{P}=0.1152\right)$. However, there

284 were significant differences among treatments $\left(\mathrm{F}_{2,567}=35.86 ; \mathrm{P}<0.0001\right)$ and treatments within 
weeks $\left(\mathrm{F}_{8,567}=6.99 ; \mathrm{P}<0.0001\right)$. Regardless of overall differences, the highest mortality was

286 observed only in week 2 with gel containing 6.0\% Permethrin, at 70\%, and in subsequent

287 bioassay times the male mortality levels were relatively low, ranging from $0 \%$ to $40 \%$.

288 The analysis of wax panel formulations (Fig. 4b) revealed significant differences among AI 289 treatments $\left(\mathrm{F}_{5,567}=196.37 ; \mathrm{P}<0.0001\right)$ and for the interaction of AI treatments by weeks $\left(\mathrm{F}_{20}\right.$, $290567=12.11 ; \mathrm{P}<0.0001)$. At week 0 , all AI treatments were statistically similar with very low 291 mortality. However, from week 2 to the end of the experiment at week 8 the wax panel 292 formulations based on Cyfluthrin and Permethrin both at $6.0 \%$ AI, which were statistically 293 similar, killed over $85 \%$ of the adult males, followed by Cyfluthrin $1.0 \%$, which differed 294 statistically from the rest of the treatments, which had only $0 \%$ to $10 \%$ mortality. The attract295 and-kill formulations based on the plastic cylinder showed a significant difference in male 296 mortality among AI treatments $\left(\mathrm{F}_{3,380}=78.15 ; \mathrm{P}<0.0001\right)$, but the interaction of AI treatments 297 by weeks was not significantly different $\left(\mathrm{F}_{12,380}=1.38 ; \mathrm{P}=0.1732\right)$.

298 The cylinder device sprayed with Cyfluthrin 2.0\% elicited significantly higher levels of 299 mortality compared to the other treatments, and it killed $75 \%$ or more of the adult males during 300 the whole experiment, except for week 0 in which it killed $50 \%$ on average (Fig. 3c).

302 3.4. Egg-laying

303 Fig. 4 shows the mean egg-laying per female P. interpunctella that were paired for 24-h with 304 males that had contacted attract-and-kill devices in wind tunnel bioassays. The statistical 305 analysis for the gel formulation (Fig. 4a) showed that there was no significant difference among 306 AI treatments $\left(\mathrm{F}_{2,570}=2.75 ; \mathrm{P}=0.6877\right)$, amount of gel $\left(\mathrm{F}_{1,570}=0.20 ; \mathrm{P}=0.6558\right)$, interaction 307 of AI treatment by amount of gel $\left(\mathrm{F}_{2,570}=0.008 ; \mathrm{P}=0.9247\right)$, interaction of AI treatment by 
308 week $\left(\mathrm{F}_{8,570}=0.70 ; \mathrm{P}=0.6877\right)$, interaction of amount of gel by week $\left(\mathrm{F}_{4,570}=0.41 ; \mathrm{P}=\right.$

$3090.7981)$ and interaction of AI treatment by amount of gel by week $\left(\mathrm{F}_{8,570}=0.28 ; \mathrm{P}=0.9721\right)$.

310 Treatment differences were found only for week 2, in which the formulations with Pyrethrin 100

$311 \mathrm{mg}$ and Permethrin $100 \mathrm{mg}$ showed the lowest averages of egg laying and were significantly

312 different from the Blank formulations (50 and $100 \mathrm{mg}$ ). However, all the remaining

313 formulations did not differ from each other and the numbers of eggs laid by females paired to

314 males that had contacted gels were relatively high.

315 In the case of the wax panel (Fig. 4b), there was a significant difference among AI treatments

$316\left(\mathrm{~F}_{5,570}=35.85 ; \mathrm{P}<0.0001\right)$ and with the interaction of $\mathrm{AI}$ treatments by weeks $\left(\mathrm{F}_{20,570}=3.28 ; \mathrm{P}\right.$

$317<0.0001)$. At week 0, there was no significant difference among treatments. From week 2 to

318 week 8 the wax panel formulations with Cyfluthrin 1.0\% and 6.0\%, and Permethrin 6.0\% were

319 statistically similar and elicited low egg laying averages compared to Blank and the formulations

320 with low percentage of Cyfluthrin (0.01 and $0.1 \% \mathrm{AI})$, which averaged over 35 eggs laid per

321 female.

322 Analysis of females paired with males that had been bioassayed against the cylinder devices

323 (Fig. 4c) showed a significant difference in egg laying among the AI treatments $\left(\mathrm{F}_{3,380}=28.98\right.$;

$324 \mathrm{P}<0.0001)$, but there was no significant interaction effect of the AI treatments by weeks $\left(\mathrm{F}_{12,380}\right.$

$325=0.87 ; \mathrm{P}=0.5746)$. In the whole experiment, the Blank treatment showed the highest egg

326 laying and was significantly different from the rest of the treatments, except at week 8, in which

327 it was similar to Permethrin 2.0\%. The Cyfluthrin $2.0 \%$ generally had the most suppressive

328 effect on number of eggs laid per female.

329

330 3.5. Egg hatching. 
Analysis of responses to the gel formulations revealed a significant difference among AI

332 treatments $\left(\mathrm{F}_{2,569}=10.21 ; \mathrm{P}<0.0001\right)$ in the percentage of eggs that hatched from those laid by

333 females paired with males from bioassays (Fig. 5a). However, there were no significant

334 differences among gel amount $\left(\mathrm{F}_{1,569}=0.01 ; \mathrm{P}=0.9492\right)$, interaction of AI treatment by gel

335 amount $\left(\mathrm{F}_{2,569}=1.79 ; \mathrm{P}=0.1679\right)$, interaction of $\mathrm{AI}$ treatment by week $\left(\mathrm{F}_{8,569}=1.82 ; \mathrm{P}=\right.$

336 0.0706), interaction of gel amount by week $\left(\mathrm{F}_{4,569}=0.40 ; \mathrm{P}=0.8098\right)$ and interaction of AI

337 treatment by gel amount by week $\left(\mathrm{F}_{8,569}=0.38 ; \mathrm{P}=0.9299\right)$. There were no significant

338 differences among AI treatments at weeks 0 and 8 . In the other weeks there were statistically

339 significant reductions in egg hatching in clutches from insecticide-treated gels, but these were

340 not substantial.

341 The experiment with the wax panel (Fig. 5b) showed significant differences in egg hatch

342 among AI treatments $\left(\mathrm{F}_{5,570}=45.57 ; \mathrm{P}<0.0001\right)$ and in the interaction of AI treatments by week

$343\left(\mathrm{~F}_{20,570}=4.05 ; \mathrm{P}<0.0001\right)$. Permethrin $6.0 \%$ and Cyfluthrin $1.0 \%$ and $6.0 \%$ were the

344 treatments with lower percentage of hatched eggs in most of the dates and these three were

345 statistically similar at the eight-week period. In general, high concentrations of Cyfluthrin and

346 Permethrin on wax panels were associated with lower percent of egg hatching compared to the

347 Blank and low percent AI of Cyfluthrin.

348 The cylinder formulation analysis (Fig. 5c) showed experiment-wide significant differences

349 in egg hatching among $\mathrm{AI}$ treatments $\left(\mathrm{F}_{3,377}=37.38 ; \mathrm{P}<0.0001\right)$. However, there was no

350 significant interaction of AI treatments by weeks $\left(\mathrm{F}_{12,377}=1.12 ; \mathrm{P}=0.3419\right)$. The percentage of

351 hatching of the insecticide treatments was significantly lower than Blank in weeks 4,6 , and 8.

352 Hatch rates were the lowest resulting from AI treatments of Cyfluthrin $2.0 \%$ in week 2 and 4 , 
353 being $8.4 \%$ and $8.0 \%$, respectively, and hatching ranged from $16.9 \%$ to $67.7 \%$ in other $\mathrm{AI}$

354 treatments.

355 


\section{Discussion}

The experiments reported here will help determine the optimal device design, pheromone

358 release technology and insecticide formulation to pursue further for development of an attract-

359 and-kill technology to control pest populations of $P$. interpunctella in commercial settings, some

360 of which were tested in subsequent research (Campos 2008). The eight-week time period

361 studied here was employed to examine a realistic time period in which a pest control company

362 might apply a typical treatment to a facility, such as frequency of insecticide sprays or aerosols

363 "fogging" applications (e.g., Arthur and Phillips, 2003), for Indianmeal moth control. Since the

364 ultimate goal of the attract-and-kill strategy is to kill enough males in a population to cause a

365 negative impact on reproduction, these experiments provided an estimate of reproductive impact

366 by killing or otherwise incapacitating male moths so that mating and reproduction with females

367 could be reduced. The reproductive fitness of individual males that had contacted an attract-and-

368 kill device was manifested by how many eggs were laid and $1^{\text {st }}$ instar larvae (percentage of eggs

369 that hatched) produced when they were paired with a virgin female immediately after treatment.

370 It is important to note that the percentage of males landing on and maintaining contact with

371 any of the three devices was consistently low at time 0 , but then improved in subsequent weeks

372 as the formulations aged. This delayed activity was probably due to the pheromone dispensing

373 system being newly exposed to air at time 0 . The commercial pheromone lures (Biolure ${ }^{\circledR}$ lures)

374 were opened from sealed storage packages and the LastCall@ gel was applied from tubes just

375 before conducting the time-0 assays. We submit that there was a relatively high release of

376 synthetic pheromone at time 0 compared to later times such that orientation to the point source

377 and sustained contact by responding males was inhibited or otherwise less than optimal.

378 Although percent contact and contact time were low at time 0 , we noted that most males 
approached the attract-and-kill device in a zig-zag flight pattern; they landed within a few

380 centimeters from the pheromone source and walked around with abdomens curved ready to mate,

381 which would be adequate to be captured in sticky traps for which the slow-release lures are

382 intended for use. Our results suggest that such lures and gels should be aged between 0 and 2

383 weeks for best use in attract-and-kill applications agains Indianmela moth. Work with

384 pheromone lures of other species has shown that initial low or high release of pheromone can

385 cause a lack of complete response or inactivation instead of full attractive response and sustained

386 contact with the source (Baker and Roelofs, 1981; Baker et al., 1981; Kuenen and Baker, 1982;

387 Hussain et al., 1994, personal observations).

388 The wax panel and cylinder devices were clearly superior to the gel formulation for

389 achieving desired moth responses. Gel formulations elicited very low contact response (20-55\%)

390 at time 0 , peak responses at the 2-week bioassay (70-85\%), and then had a sharp decline in

391 activity from week 4 to week 8 . Thus, the gel formulation could not sustain activity for

392 substantial male-killing through the eight-week study, which was not addressed in the

393 experiments by Nansen and Phillips (2004), and our data suggest this gel would probably be

394 ineffective in a practical application for 8 weeks. Alternatively, the Biolure ${ }^{\circledR}$ pheromone lures

395 used with the wax panel and cylinder devices had characteristic low activity for contact only at

396 time 0, but showed increased and sustained activity for male response from week 2 onward, with

397 essentially $100 \%$ male contact and contact times of several seconds. Contact time with the

398 devices was similarly much higher for the wax panels and cylinders that were baited with

399 Biolure ${ }^{\circledR}$, compared to the gel formulation, and this was maintained from week 2 until the 8-

400 week end of the study. 
Higher and sustained mortality levels for certain formulations of wax panels and plastic

402 cylinders compared to the gel can be attributed to the more effective pheromone lure system, but 403 also probably to the overall larger surface area of the device itself, compared to the small amount 404 of material presented by the gel formulations. High contact times were recorded for moths 405 responding to wax panels and cylinders, and it was observed that during these times the male 406 moths would move around over the surface of the device, which probably contributed to better 407 contact with insecticide and the ultimate toxicity. Higher male mortality levels, specifically on 408 the wax panels with 6.0\% Cyfluthrin and 6.0\% Permethrin, and on the plastic cylinder with 2.0\% 409 Cyfluthrin, corresponded to high male mortality, subsequent low levels of egg laying and 410 ultimately low hatch rates of those eggs. These results suggest that the wax panel formulation 411 would be effective for Indianmeal moth suppression in practical applications. The results 412 indicate that higher concentrations, greater than $1.0 \%$, of the synthetic pyrethroids Cyfluthrin and 413 Permethrin, result in the most effective attract-and-kill devices when the wax panel and plastic 414 cylinder were used.

415 Organically-compliant natural Pyrethrin at $2.0 \%$ was not effective enough on the plastic 416 cylinder at any bioassay time during the eight-week period to pursue further applied research. 417 Permethrin at $2.0 \%$ on the cylinder was also not effective compared to $2.0 \%$ Cyfluthrin, and this 418 may have been due to physical or chemical interaction with the substrate that resulted in lowered 419 activity compared to that of the same compound on another substrate (Campos and Phillips, 420 2010). Future research will need to involve studies with formulations of high concentration 421 Cyfluthrin or Permethrin on wax panels, or Cyfluthrin on plastic cylinders with P. interpunctella 422 populations in experimental or commercial food establishments. 
Pheromone-based pest management technologies are gaining popularity with stored-product

424 systems because of their relative safety for food, workers and the environment, and the reduction 425 or elimination of synthetic insecticides from these systems (Phillips and Throne, 2010). Mating

426 disruption of stored-product moth species using the same synthetic pheromone used in this

427 current work has been well studied (e.g., Ryne et al., 2007) and the method was registered for

428 pest control by the lead regulatory agency of the USA (EPA, 2006). The attract-and-kill method

429 studied here, like similar systems studied in other agricultural settings (e.g., the fruit pest systems

430 of Evenden et al., 2005, and Krupke et al. 2002), uses sysnthetic sex pheromone at release levels

431 similar to those used in moth monitoring traps, and deploys very small amounts of synthetic

432 insecticide precisely placed point sources that can be retrieed at the end for the control program,

433 thus leaving no or very little residue at the site. The most active insecticide treatments

434 determined in the current work, the pyrethroids Cyfluthrin and Permethrin, are already widely

435 registered for use in stored-product and food environments (Arthur and Phillips, 2003), thus we

436 project that attract-and-kill systems for storage moths like those studied here might readily

437 receive regulatory approval if developed into commercial pest control products.

439 Aknowledgements

440 The authors thank Dr. Mark Payton for advice on statistical analyses and also Drs. Jack Dillwith, 441 Brad Kard and Mark Payton for comments on earlier drafts of this manuscript. Technical

442 assistance and logistical support was provided by Edmond Bonjour and his staff for maintenance

443 of insect colonies. We appreciate the generous supplying of test materials from IPM

444 Technologies of Portland, Orgeon, USA and also from Suterra in Bend, Oregon, USA. Financial

445 support was provided by grants from the USDA Risk Avoidance and Mitigation Program 
446 (Project No. S05035), the Oklahoma Agricultural Experiment Station, and the Kansas

447 Agricultural Experiment Station.

448 


\section{References}

450 Arthur, F.H., Highland, H.A., Mullen, M.A., 1991. Efficiency and longevity of two commercial sex pheromone lures for Indianmeal moth and Almond moth. (Lepidoptera: Pyralidae).

453 Arthur, F.H., Phillips, T.W., 2003. Stored-product insect pest management and control. Food Plant Sanitation (ed. by YH Yui, BL Bruinsma, JR Gorhap, W Nip, PS Tong \& P Ventresca), Marcel Dekker, New York, NY, pp. 341-348.

Baker, T.C., Roelofs, W.L., 1981. Initiation and termination of Oriental fruit moth male response to pheromone concentrations in the field. Environmental Entomology 10: 211-218.

Baker, T.C., Meyer, W., Roelofs, W.L. 1981. Sex pheromone dosage and blend specicity of response by Oriental fruit moth males. Entomologia Experimentalis et Applicata 30: 269-

461 Brady, U.E., Norlund, D.A.,Daley, R.C., 1971. The sex stimulant of the Mediterranean flour moth Anagasta kuehniella. Journal Georgia Entomological Society 6: 215-17.

Burkholder, W.E., Ma, M., 1985. Pheromones for monitoring and control of stored-product 279. insects. Annual Review of Entomology 30: 257-272.

Campos, M., 2008. Attract-and-Kill Methods for Plodia interpunctella, (Lepidoptera: Pyralidae), and Comparisons with other Pheromone-Based Methods. Ph.D. Dissertation, Oklahoma State Unviersity, $114 \mathrm{pp}$.

Campos, M., Phillips, T.W., 2010. Contact toxicity of insecticides for attract-and-kill applications against adult Plodia interpunctella (Hübner) (Lepidoptera: Pyralidae). Pest Manag. Sci. 66: 752-761. 
El-Sayed, A.M., Suckling, D.M., Wearing, C.H., Byers, J.A. 2006. Potential of mass trapping for long-term pest management and eradication of invasive species. Journal of Economic Entomology. 99: 1550-1564.

[EPA] Environmental Protection Agency. 2006. Lepidopteran pheromones; exemption from a requirement of a tolerance. Fed. Regist. 71:45395-400.

Evenden, M.L., McLaughlin, J.R., 2004. Initial development of an attracticide formulation against the Oriental fruit moth, Grapholita molesta (Lepidoptera: Tortricidae). Environmental Entomology 33: 213-220.

Evenden, M.L., McLaughlin, J.R., 2005. Male Oriental fruit moth response to a combined pheromone-based attracticide formulation targeting both Oriental fruit moth and Codling moth (Lepidoptera: Tortricidae). Journal of Economic Entomology 98: 317-325.

Evenden, M.L., McLaughlin, J.R., Czokajlo, D., 2005. Effects of exposure to pheromone and insecticide constituents of an attracticide formulation on reproductive behavior of Oriental fruit moth (Lepidoptera: Tortricidae). Journal of Economic Entomology 98: 334-341.

Hussain, A., Phillips. T.W., AliNiazee, M.T., 1994. Responses of Tribolium castaneum to different baits and traps in the laboratory. Proceedings of the Sixth International Working Conference on Stored-Product Protection (ed. by BR Champ, HJ Banks, \& Highley E). CABI Press. Canberra, AU, pp. 406-409.

Krupke, C.H., Roitberg, B.D., Judd, G.J.R., 2002. Field and laboratory responses of male Codling moth (Lepidoptera: Tortricidae) to a pheromone-based attract and kill strategy. Environmental Entomology 31: 189-197. 
493 Kuenen, L.P.S., Baker, T.C., 1982. Optomotor regulation of ground velocity in moths during

494 flight to sex pheromone at different heights. Physiological Entomology 7: 193- 202.

495 Kuwahara, Y., Kitamura, C., Takahashi, S., Hara, H., Ishii, S., Fukami. H., 1971. Sex

496 pheromone of the almond moth and the Indian meal moth: cis-9,trans-12-tetradecadienyl

497 acetate. Science 171:801-802.

498 Kuwahara, Y., Cassida, J.E., 1973. Quantitative analysis of the sex pheromone of several 499 phycitid moths by electrocapture gas chromatography. Agricultural and Biological $500 \quad$ Biochemistry 37:681-684.

501 Lanier, G.N., 1990. Principle of attraction-annihilation: mass trapping and other means. Behavior-Modifying Chemicals for Insect Management, Applications of Pheromones and other Attractants (ed. by RL Ridgway, RM Silverstein \& Inscoe MN). Marcel Dekker, New York, NY. pp. 25-45.

505 Nansen, C., Phillips, T.W., 2004. Attractancy and toxicity of an attracticide for Indianmeal 506 moth, Plodia interpunctella (Lepidoptera: Pyralidae). Journal of Economic Entomology

508 Phillips, T.W., 2006. The Science and Technology of Postharvest Insect Control: Challenges, Accomplishments and Future Directions. Insect Management for Food Storage and Processing, $2^{\text {nd }}$ Ed. (ed. by J Heaps). American Association of Cereal Chemists, pp. 211-

512 Phillips, T.W., Cogan, P.M., Fadamiro, H.Y., 2000. Pheromones. Alternatives to Pesticides in 513 Stored-Product IPM (ed. by Subramanyam Bh \& Hagstrum DW). Kluwer Academic 514 Publishers. Boston, MA, pp. 273-302. 
515 Phillips, T.W., Throne, J.E., 2010. Biorational Approaches to Managing Stored-Product Insects. $516 \quad$ Annual Review of Entomology. 55: 375-397.

517 Ryne, C., Svensson, G.P., Anderbrant, O., Löfstedt, C., 2007. Evaluation of long-term mating 518 disruption of Ephestia kuehniella and Plodia interpunctella (Lepidoptera: Pyralidae) in 519 indoor storage facilities by pheromone traps and monitoring of relative aerial 520 concentrations of pheromone. Journal of Economic Entomology. 100:1017-25

521 SAS Institute., 2005. SAS/STAT users guide, version 9. SAS Institute, Cary, NC.

522 Soderstrom, E.L., Brandl, D.G., Vick, K.W., Coffelt, J.A., 1980. Evaluation of synthetic sex 523 pheromone. Insecticide and Acaricide Test 5: 207-208.

524 Sower, L.L., Vick, K.W., Tumlinson, J.H., 1974. (Z,E)-9-12-Tetradecadien-1-ol: A chemical 525 released by female Plodia interpunctella that inhibits the sex pheromone response of 526 male Cadra cautella. Environmental Entomology 3: 120-122.

527 Teal, P.E.A., Heath, R.R., Dueben, B.D., Coffelt, J.A., Vick, K.W., 1995. Production and 528 529

530 Vick, K.W., Coffelt, J.A., Mankin, R.W., Soderstrom, E.L., 1981. Recent developments in the 531 use of the pheromones to monitor Plodia interpunctella and Ephestia cautella.

532 Management of insect pest with semiochemicals (ed. by ER Mitchell). Plenum 533 Publishing, New York, NY, pp. 19-28.

534 Vick, K.W., Koehler, P.G., Neal, J.J., 1986. Incidence of stored-product Phycitinae moth in food 535 distribution warehouses as determined by sex pheromone-baited traps. Journal of $536 \quad$ Economic Entomology 79: 936-939. 
537 Zhu, J., Ryne, C., Unielus, C.R., Valeur, P.G., Löfstedt, C., 1999. Reidentification of the female 538 sex pheromone of the Indianmeal moth Plodia interpunctella: evidence for a fourcomponent pheromone blend. Entomologia Experimentalis et Applicata 92: 137-146. 


\section{Figure Legends}

543 Fig. 1. Mean percentage $(\%)$ of $P$. interpunctella adult males $( \pm \mathrm{SE})$ that landed onto three attract-

544 and-kill formulations [a) Gel, b) Wax panel and c) Plastic cylinder] in a wind tunnel during an

545 eight-week aging period. Means across weeks per each formulation followed by the same letter

546 (Upper case) and means for all formulations at given week followed by the same letter (Lower

547 case) are not significantly different at $P<0.05$. Analysis was conducted separately for each

548 attract-and-kill formulation. $\mathrm{Py}=$ Pyrethrin, $\mathrm{Pe}=$ Permethrin, $\mathrm{Cy}=$ Cyfluthrin, Blank $=$

549 Pheromone only. All treatments for week 2-8 of wax panel formulation were A,a.

551 Fig. 2. Mean time in seconds $( \pm \mathrm{SE})$ that $P$. interpunctella adult males were in contact with the

552 attract-and-kill formulations [a) Gel, b) Wax panel and c) Plastic cylinder] in a wind tunnel

553 during an eight-week aging period. Means across weeks per each formulation followed by the

554 same letter (Upper case) and means for all formulations at given week followed by the same

555 letter (Lower case) are not significantly different at $P<0.05$. Analysis was conducted separately

556 for each attract-and-kill formulation. Py = Pyrethrin, Pe = Permethrin, $\mathrm{Cy}=$ Cyfluthrin, Blank = 557 Pheromone only.

559 Fig. 3. Mean percent (\%) mortality of $P$. interpunctella adult males $( \pm$ SE) for each attract-and-

560 kill formulation [a) Gel, b) Wax panel and c) Plastic cylinder] in a wind tunnel during an eight-

561 week aging period. Means across weeks per each formulation followed by the same letter (Upper

562 case) and means for all formulations at given week followed by the same letter (Lower case) are

563 not significantly different at $P<0.05$. Analysis was conducted separately for each attract-and-

564 kill formulation. $\mathrm{Py}=$ Pyrethrin, $\mathrm{Pe}=$ Permethrin, $\mathrm{Cy}=$ Cyfluthrin, Blank $=$ Pheromone only. 
566 Fig. 4. Mean number $( \pm \mathrm{SE})$ of laid eggs per $P$. interpunctella female for each attract-and-kill

567 formulation [a) Gel, b) Wax panel and c) Plastic cylinder] in a wind tunnel during an eight-week

568 aging period. Means across weeks per each formulation followed by the same letter (Upper case)

569 and means for all formulations at given week followed by the same letter (Lower case) are not

570 significantly different at $P<0.05$. Analysis was conducted separately for each attract-and-kill

571 formulation. $\mathrm{Py}=$ Pyrethrin, $\mathrm{Pe}=$ Permethrin, $\mathrm{Cy}=$ Cyfluthrin, Blank $=$ Pheromone only.

573 Fig. 5. Mean percent $(\%)$ of hatched egg $( \pm$ SE) of $P$. interpunctella for each attract-and-kill

574 formulation [a) Gel, b) Wax panel and c) Plastic cylinder] in a wind tunnel during an eight-week

575 aging period. Means across weeks per each formulation followed by the same letter (Upper case)

576 and means for all formulations at given week followed by the same letter (Lower case) are not

577 significantly different at $P<0.05$. Analysis was conducted separately for each attract-and-kill

578 formulation. $\mathrm{Py}=$ Pyrethrin, $\mathrm{Pe}=$ Permethrin, $\mathrm{Cy}=$ Cyfluthrin, Blank $=$ Pheromone only.

580 Supp. Fig. 1. Attract and kill formulations tested under in a wind tunnel: a) Gel with pheromone

581 and insecticide on a microscope slide (left) with moth responding upwind from right; b) Wax

582 panel impregnated with insecticide (note pheromone lure in center hole of panel); c) Plastic

583 cylinder coated with insecticide. Male moth in each photo is about $6.0 \mathrm{~mm}$ long. 


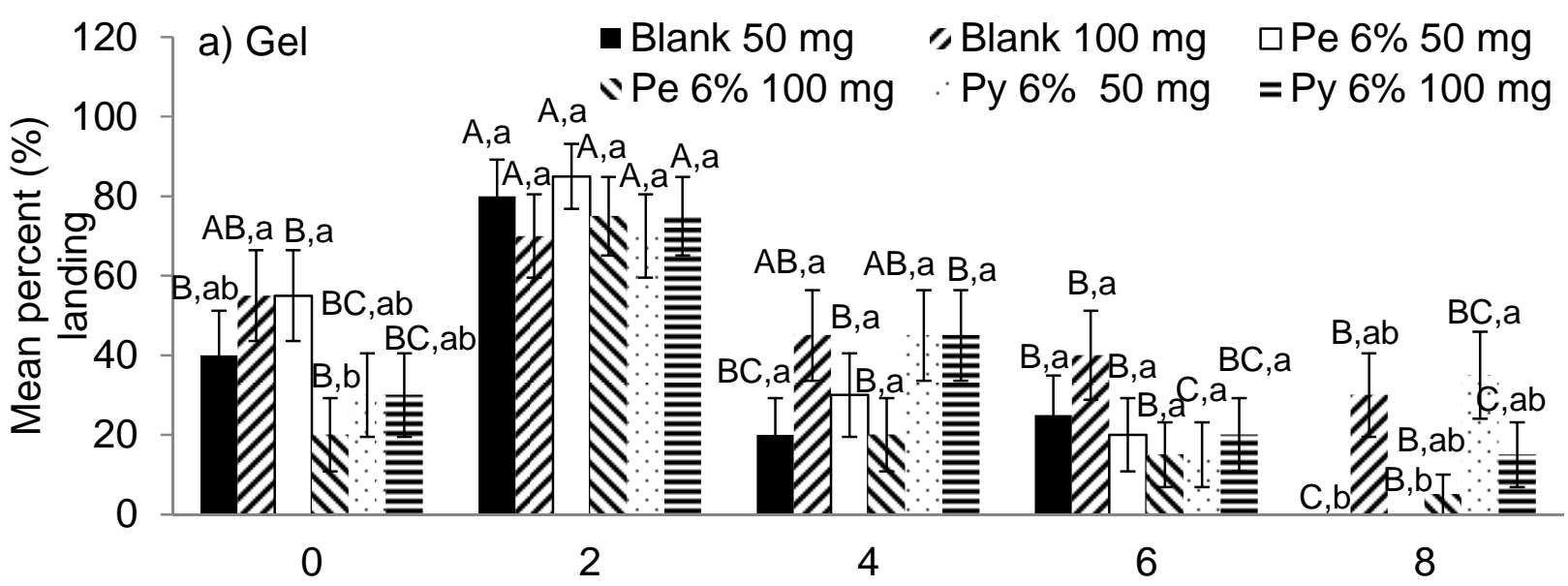

587
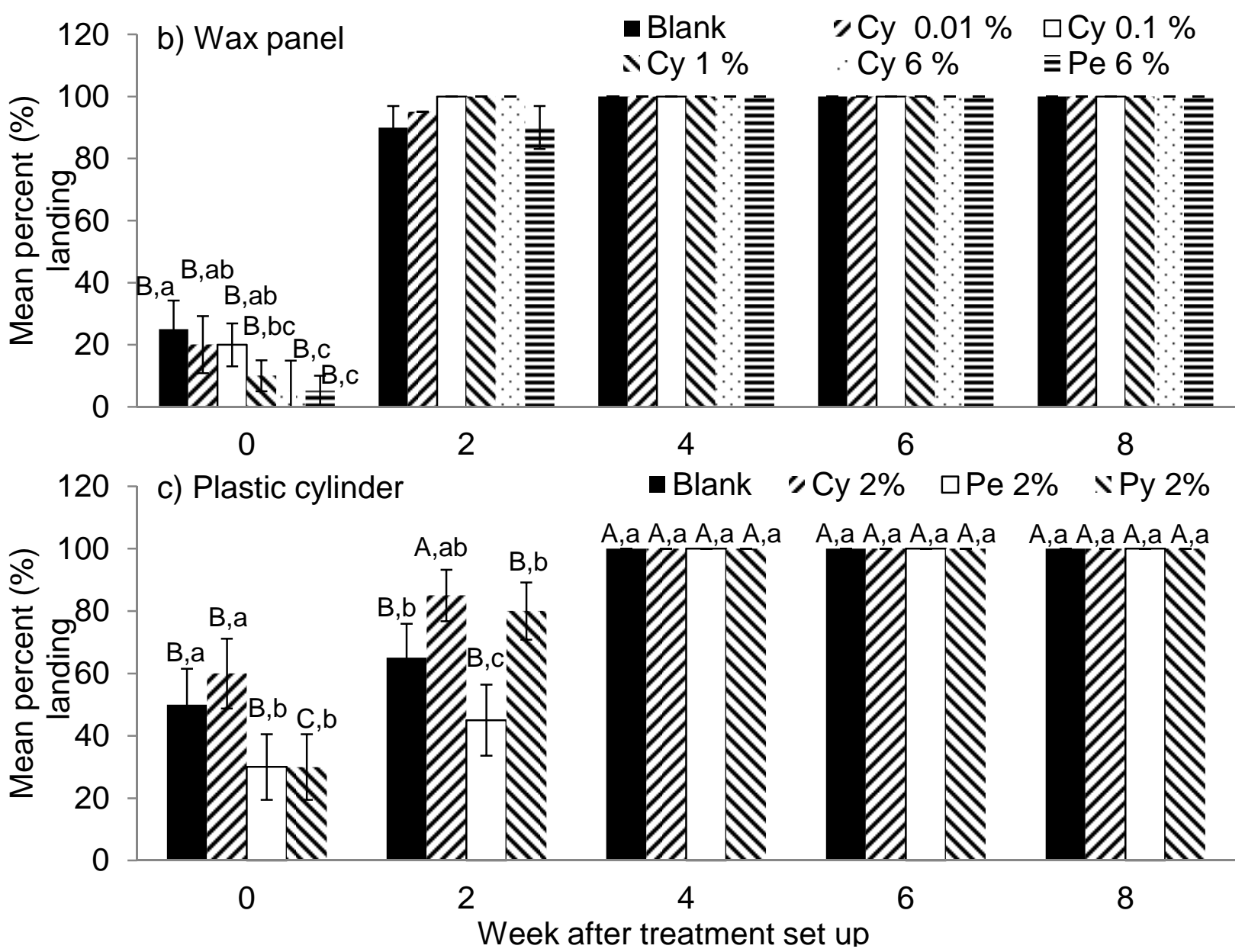

590 Fig. 1.

591

592

593

594

595

596 
598

599

600

601

602

603

604

605

606

607
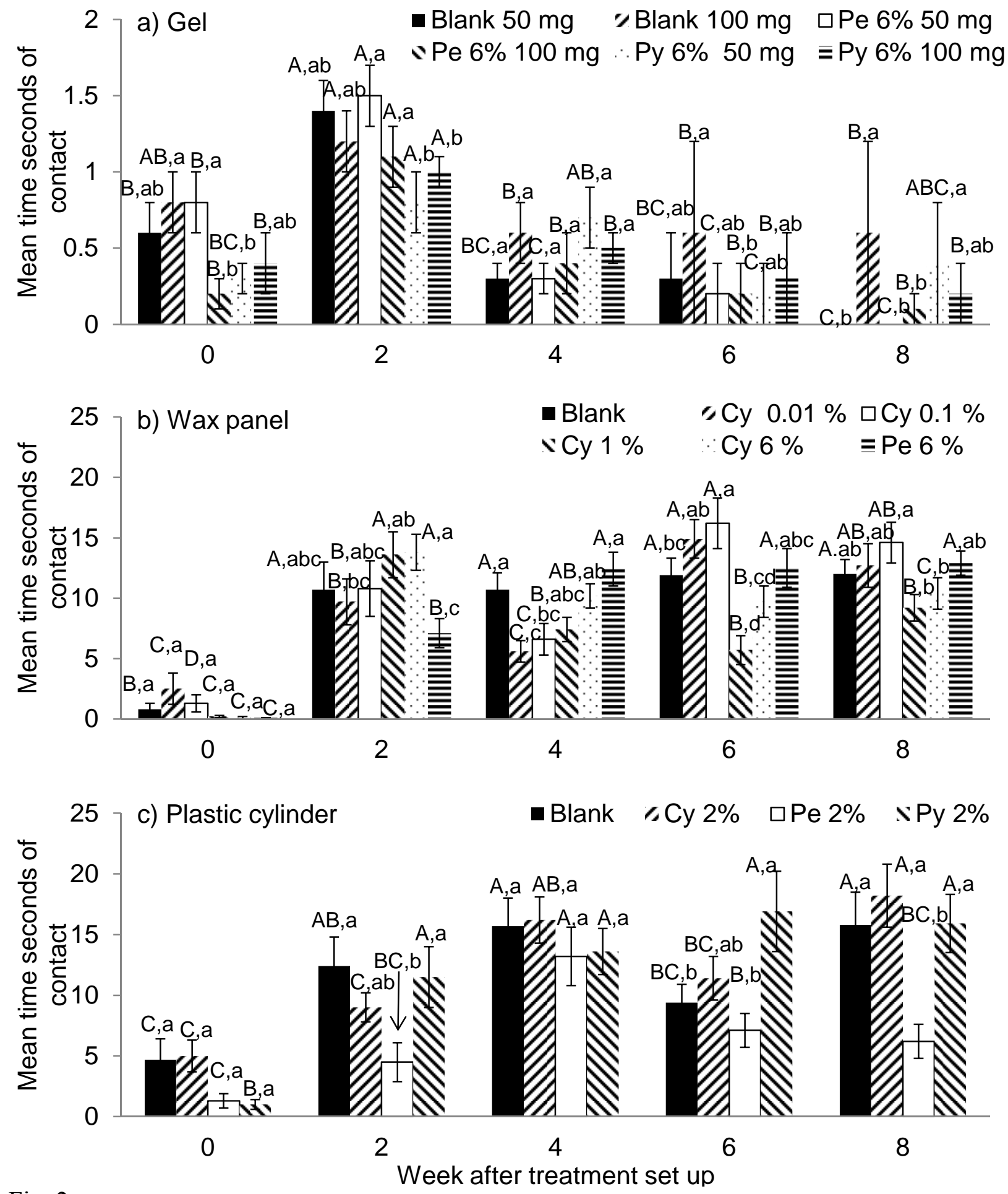

Fig. 2. 
608

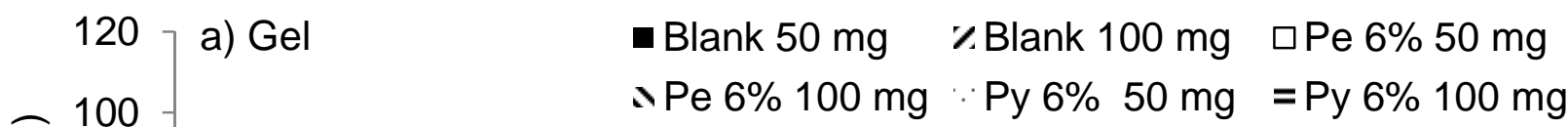

609

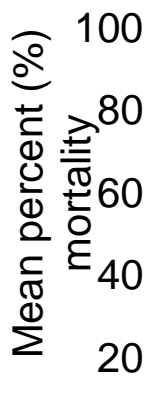

$$
0
$$

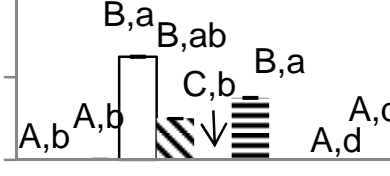

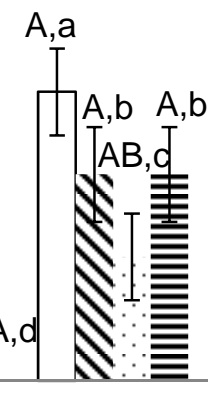

2

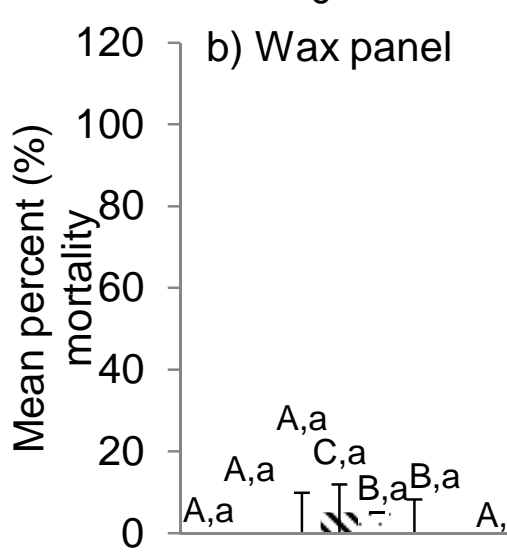

4

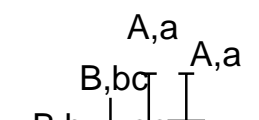

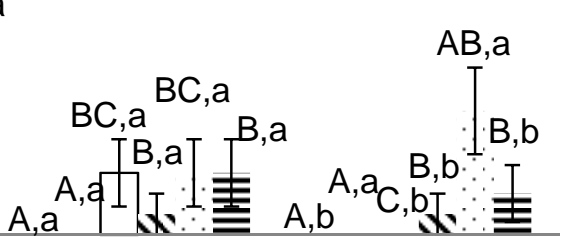

6

$8 \%$

610

611

612

613

614

615

616

617

618

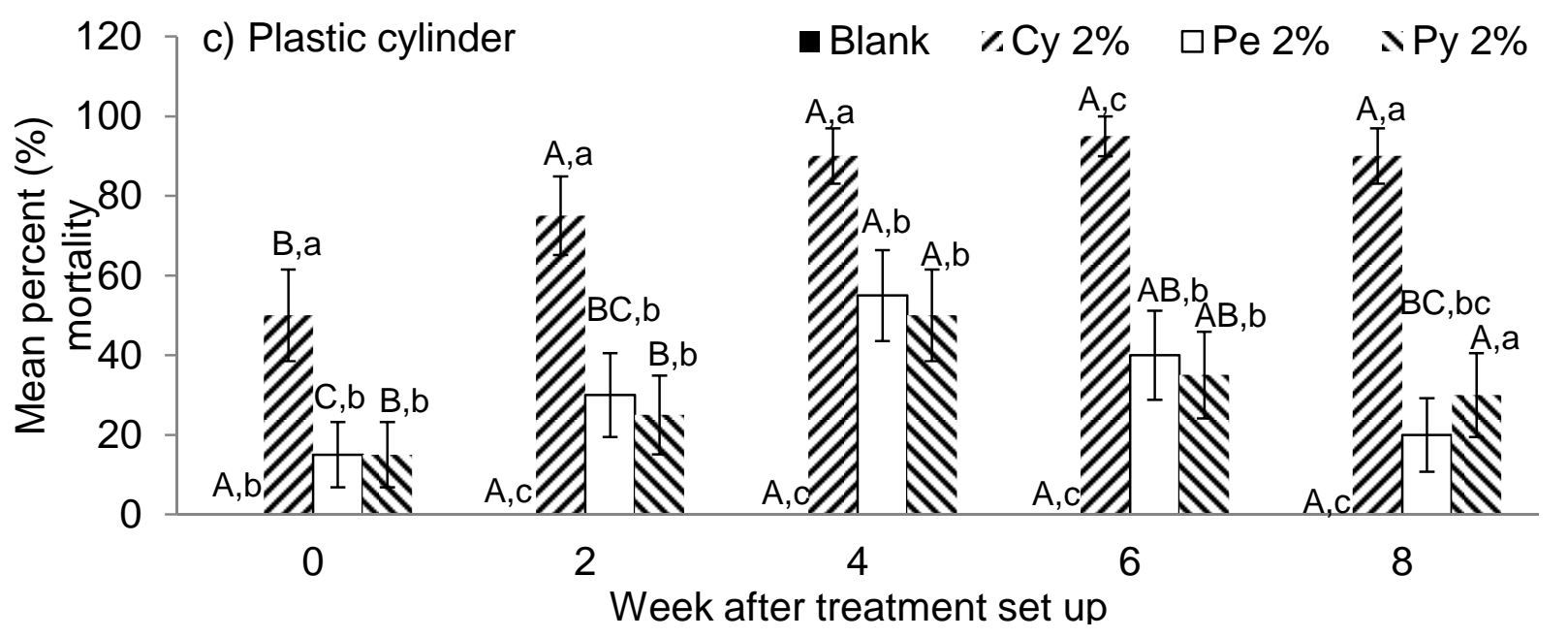

Fig. 3. 
619

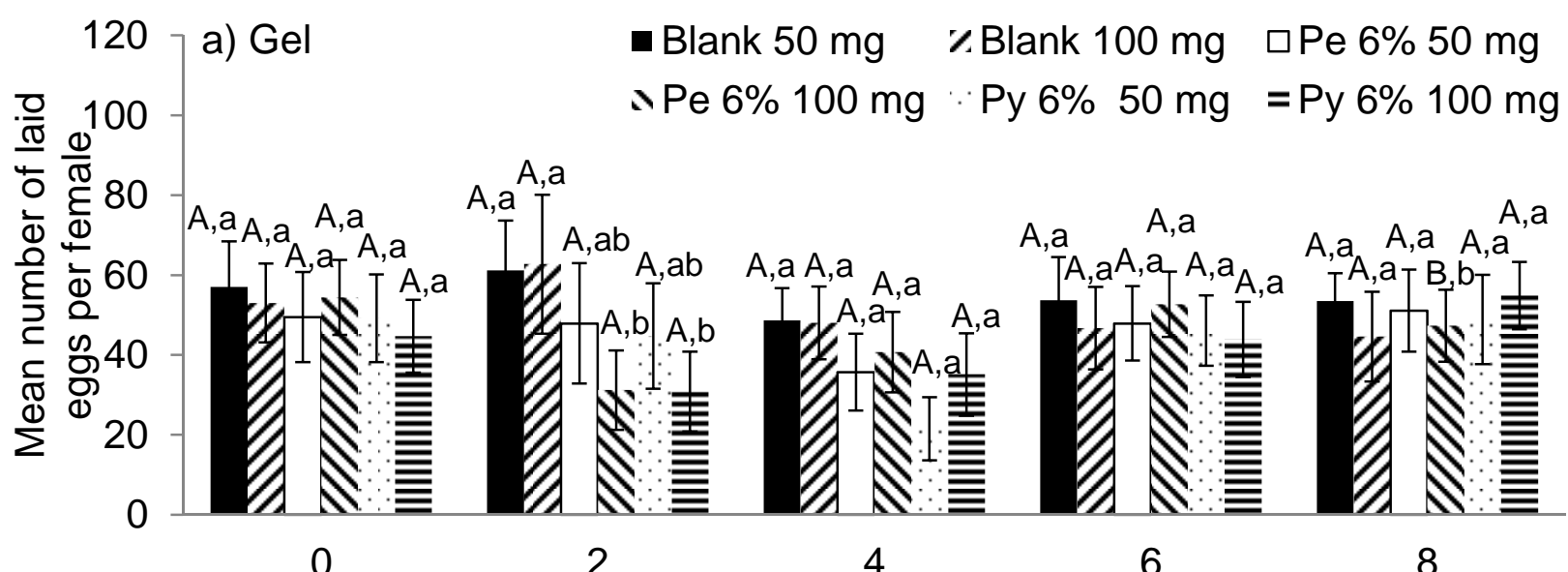

620

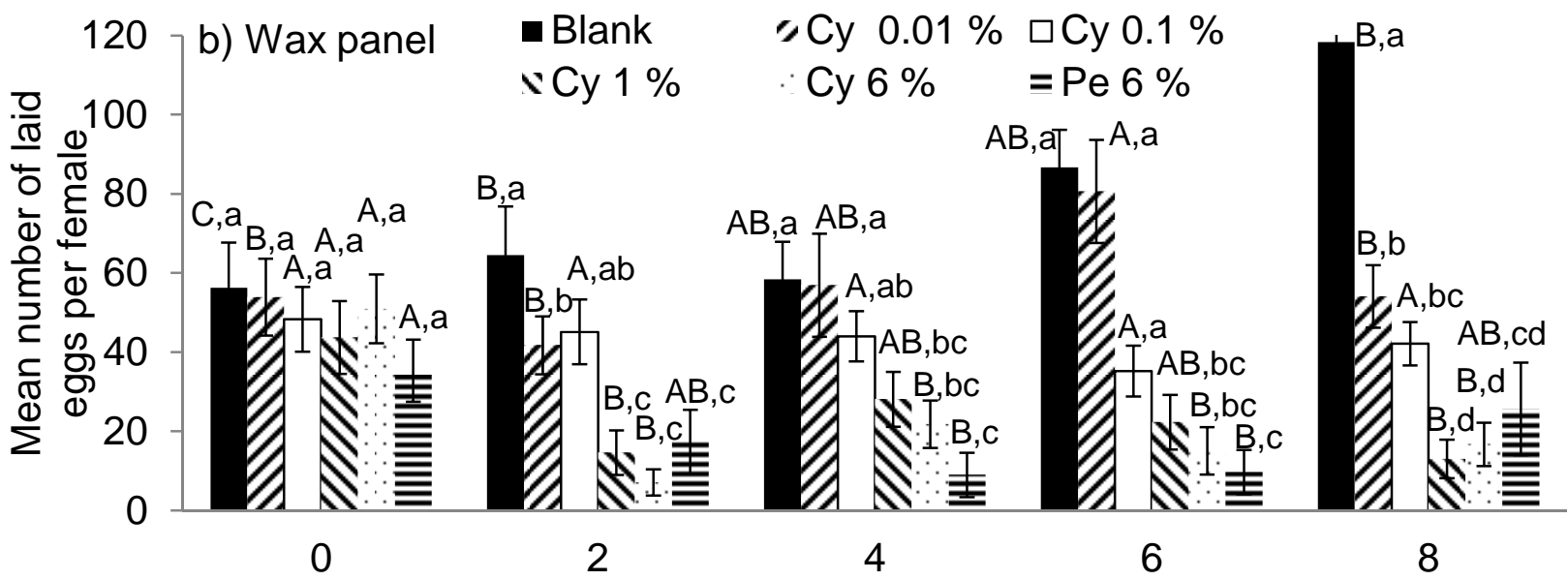

621

120 c) Plastic cylinder

-Blank ‘Cy $2 \% \quad \square$ Pe $2 \%$ जPy $2 \%$

$\frac{.}{\frac{0}{\sigma}} \frac{\Phi^{100}}{\frac{\sigma}{\sigma}} 80$

बे

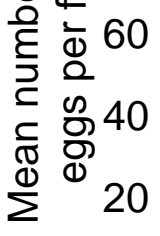

0

622

623

Fig. 4.

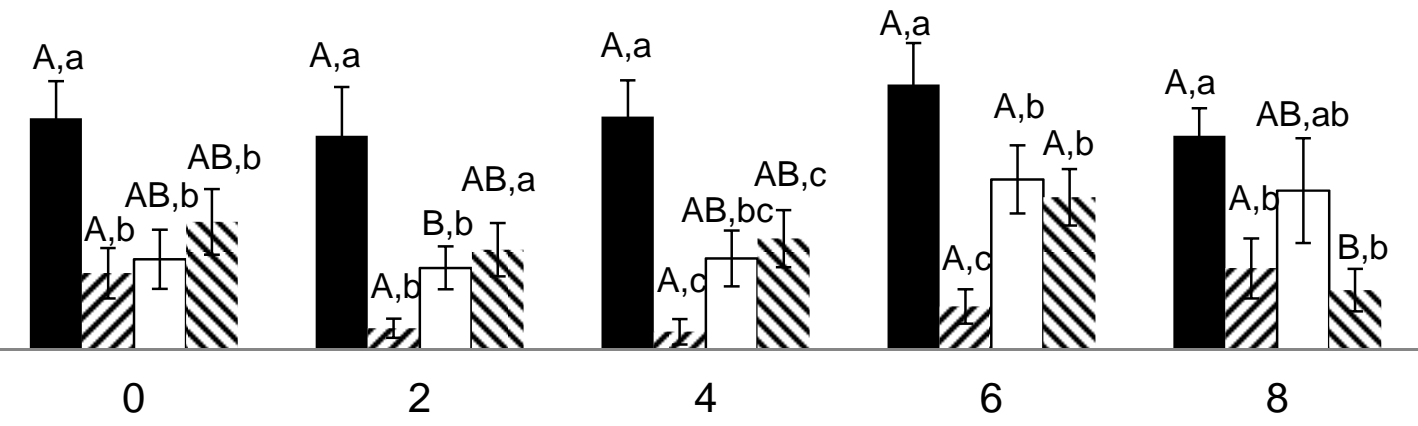

624

625

626

627

628

629 
630

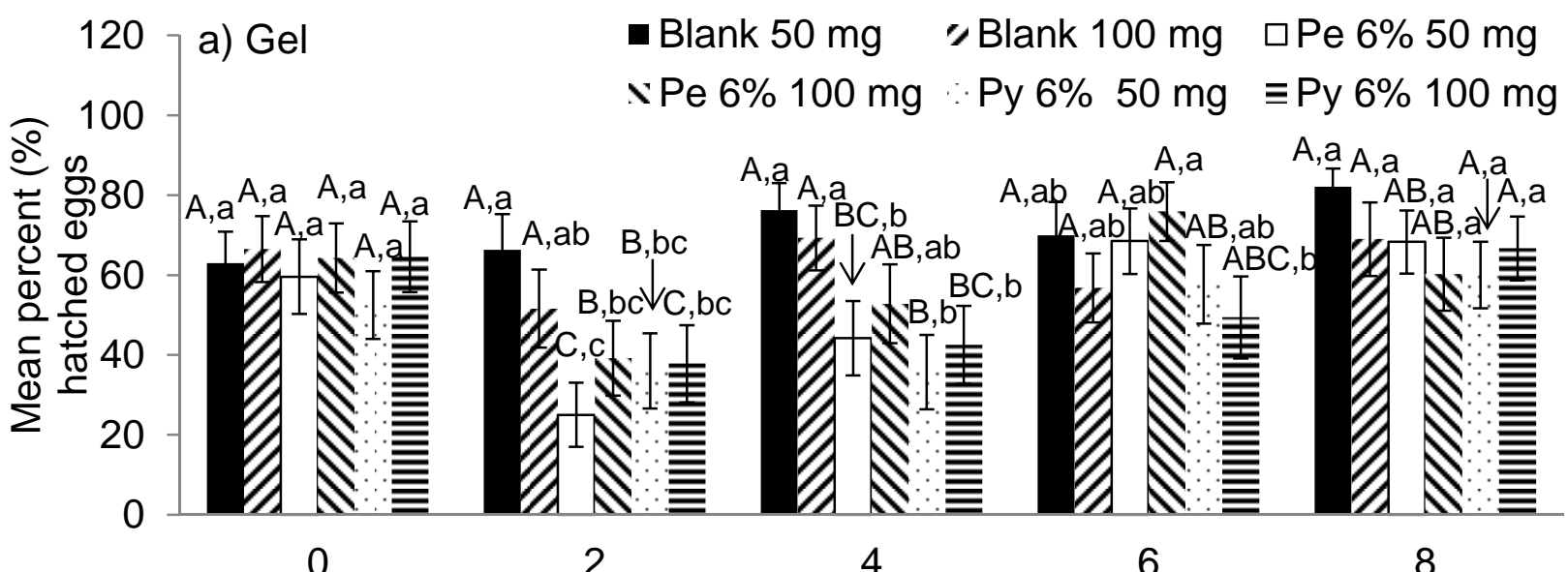

631

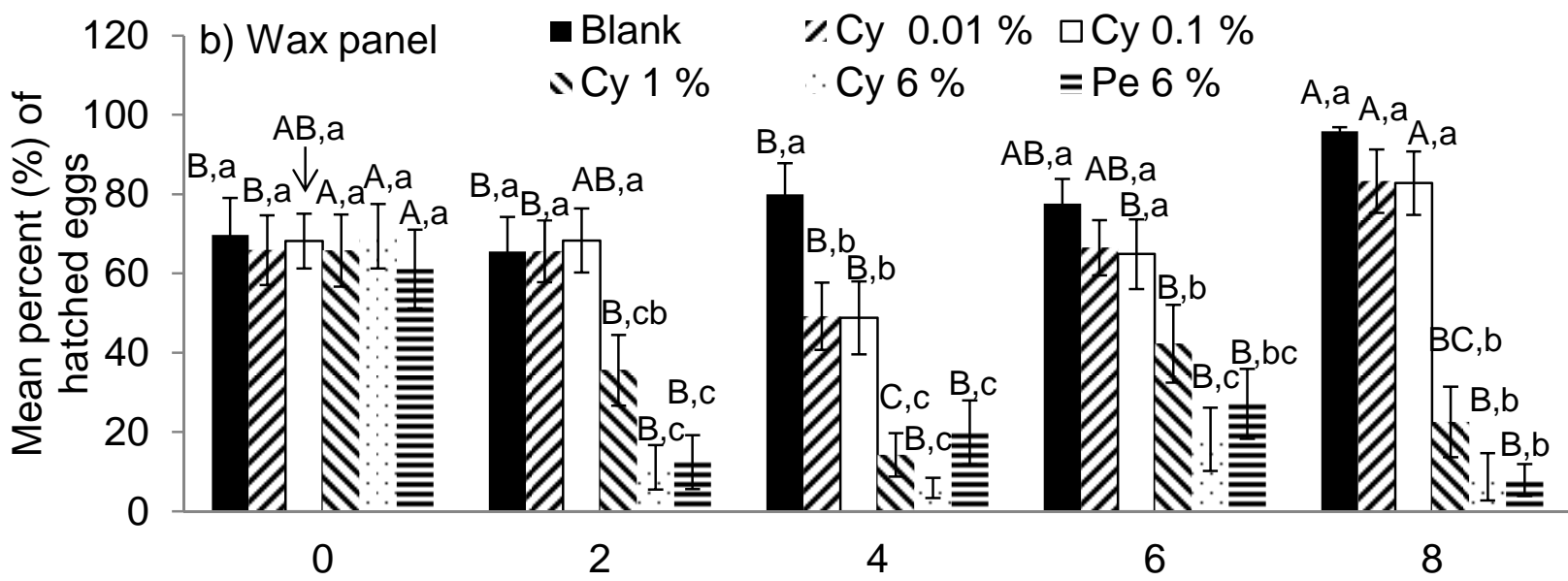

632

120 ) Plastic cylinder

-Blank "Cy $2 \% \quad$ aPe $2 \% \quad$ sPy $2 \%$

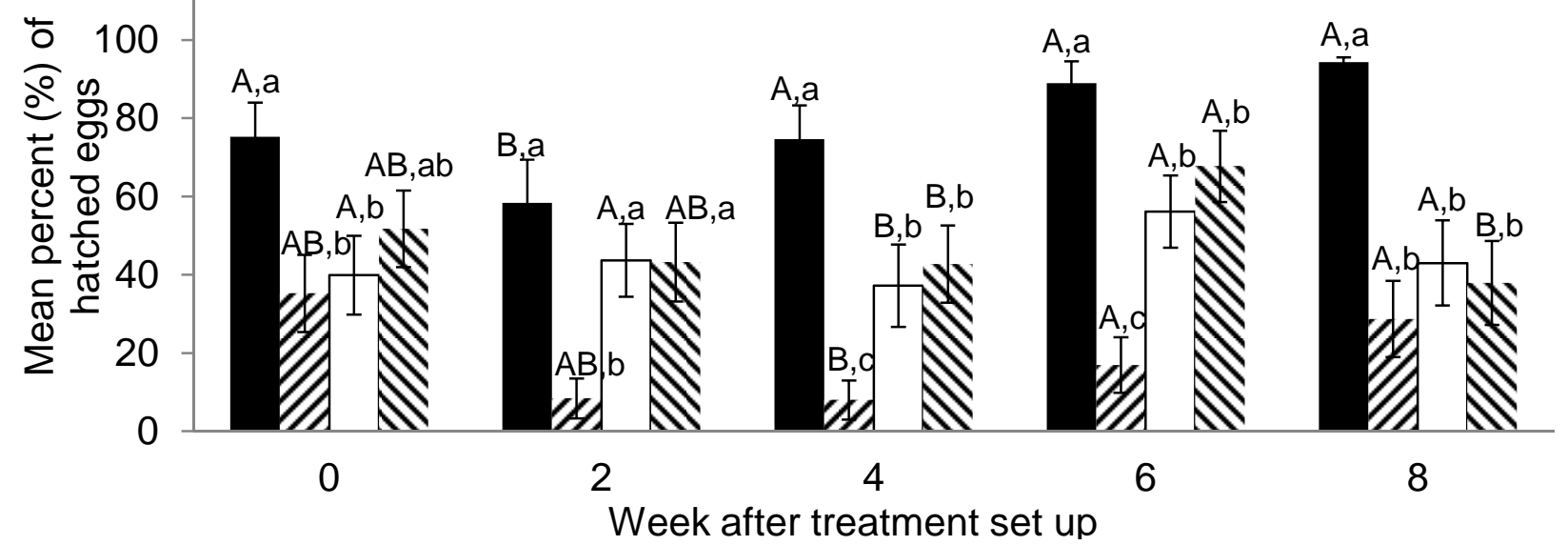

633

Fig. 5.

635 